\title{
A note on interresponse time distributions during generalization testing'
}

WILLIAM R. SEWELL AND STEPHEN B. KENDALL

UNIVERSITY OF ALABAMA

\begin{abstract}
Abstraet
Following variable interval training a pigeon was reinforced for responding to $\mathrm{S}+(1099 \mathrm{cps}$ tone) but was not reinforced for responding during $\mathrm{S}-$ (no tone). When discrimination was stable test stimuli were introduced at preselected (formerly S-) periods. Interresponse time (IRT) distributions were obtained during presentation of stimuli. Minimal changes occurred in the IRT distributions for test stimuli relative to those for St.
\end{abstract}

\section{Problem}

Jenkins \& Harrison (1960) studied the effects of differential and nondifferential training on auditory generalization in the pigeon finding that steeper gradients were obtained following differential training. Guttman \& Kalish (1956) found in studying wavelength gradients that as the test stimulus values deviated more from the training stimulus pigeons generally responded more slowly.

What does responding more slowly mean? In steady state generalization where more reinforcements are received at 550 millimicrons than at other wavelengths "short IRT peaks" seem insensitive to stimulus variation. Fewer intermediate IRT's occur at or near 550 millimicrons than elsewhere (Blough, 1963).

The purpose of this study consisted in obtaining separate IRT distributions for responses emitted to test stimuli so that response patterning as well as rate changes could be investigated.

Use of a probe technique in generalization testing results in at least two advantages: (1) Interaction of test tones via serial effects on responding may be evaluated. (2) Total number of reinforcements possible during S+ presentation is not attenuated making interaction effects of extinction less likely (Skinner, 1950).

\section{Method}

The $\mathrm{S}$ was one experimentally naive white Carneaux pigeon maintained at $80 \%$ of its free feeding weight. A standard one cubic foot experimental chamber containing a one key response panel was used. Chamber and response key illumination was provided by white and green 7 -watt lamps, respectively. Access to grain for $4.5 \mathrm{sec}$. was accompanied by magazine light onset and extinction of the chamber and key lamps. Standard programming equipment was used. Pure tones were delivered through a ceiling mounted speaker at $80 \mathrm{db}$ amplification.

Twenty-five sessions of variable interval VI $30-\mathrm{sec}$. and VI 1-min. schedules of reinforcement in the presence of a $1099 \mathrm{cps}$ tone preceded discrimination training. From session 26 responding was reinforced on a VI 1 schedule in the presence of $1099 \mathrm{cps}$ tone (S+) and not reinforced in the absence of tone (S-). Working periods, separated by 30 sec. black out intervals (time outs), alternated in an order which precluded the responses coming under the control of stimuli other than S+ or S-.

During generalization testing tones other than $\mathrm{S}+$ were introduced in place of S- periods. Proportions of time spent in S+ between test tone presentations were roughly equivalent. Risley (1964) used a similar technique.

Test stimuli equally spaced on a logarithmic scale of frequency were of the following frequencies: $315 \mathrm{cps}$, $480 \mathrm{cps}, 720 \mathrm{cps}, 1600 \mathrm{cps}, 2400 \mathrm{cps}$, and $3600 \mathrm{cps}$. Serial presentation of test tones proceeded from 315 to $3600 \mathrm{cps}$ then from 3600 to $315 \mathrm{cps}$ omitting the 1099 cps tone.

\section{Results}

Figure 1 illustrates a gradient of generalization. On the abscissa $\mathrm{S}+$ and the test stimuli are represented by their respective values. On the ordinate are rates in responses per second. Rate measures and percentage of responses in any class interval for an IRT distribution are an average across 40 stimulus presentations for $\mathrm{S}+$ and across two test stimulus presentations for any one session, then across two test sessions separated by one week. Response rates and IRT distributions for the same two stimuli or for two sessions were not different.

In the lower center of the figure is the IRT distribution (IRT classes .2 sec. wide) for responses to the training stimulus over a five day period prior to the second test session. Under each test stimulus value is its IRT distribution representing the percentage of responses plotted against IRT classes. There appeared to be little disruption either in overall responding or in "patterning" as a result of the testing procedure per se. The number in parenthesis represents the total number of responses to a stimulus.

Other data (Sewell, 1965) showed that for class intervals 10 and above the distribution is flat. Increases in percentage of responses in the category (black bar) are an artifact of representation by too few class intervals.

A flat distribution characterized by the IRT's for $3600 \mathrm{cps}$, probably represents too small a sample of responses to allow an adequate distribution, irrespective of the phenomenon of generalization.

All distributions are similar with the exception of that for the $3600 \mathrm{cps}$ tone. Each mode is in the third class interval and there is generally a progressive decrease in the percentage of responding on either side of the modal value. The decline is somewhat more gradual toward the upper end of the continuum. Generally the category containing the next highest percentage of responses is the fourth category. 


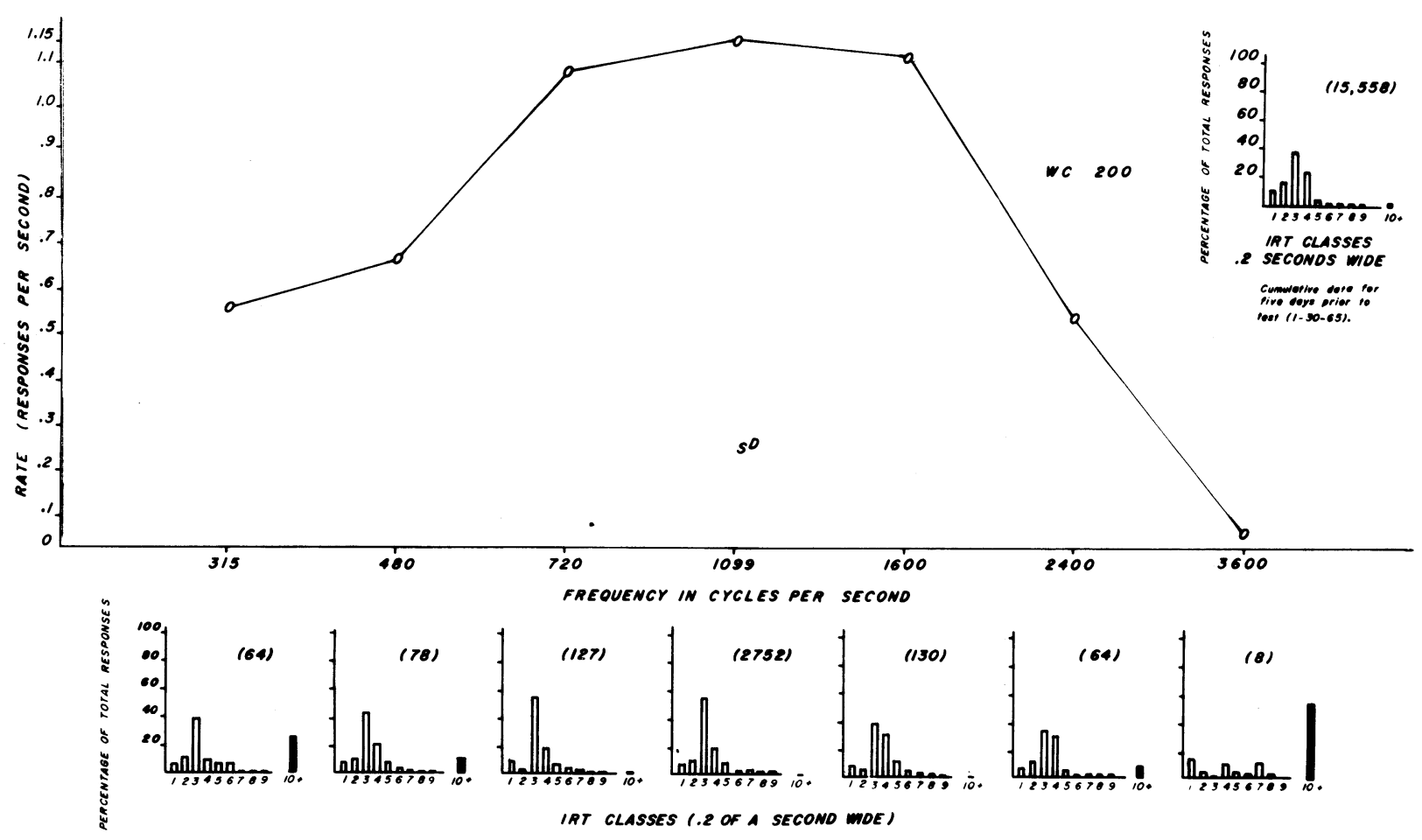

Fig. 1. A generalization gradient with rate in responses per second plotted against frequency in cycles per second. IRT distributions for each stimulus with percentage of responses plotted against IRT classes. One IRT distribution of five days responses to $\mathbf{S}+$.

\section{Diseussion}

Variability in response topography (Antonitis, 1951) and in IRT measures (Millenson \& Hurwitz, 1961) has been shown to occur during extinction. Such an occurrence has been postulated as a factor contributing toward a shift in response patterning during generalization testing.

The number of long IRT's increase during extinction tests of generalization (Blough, 1963). Particular response patterns may be critical determinants of the shape of generalization gradients (Hearst, Koresko, \& Poppen, 1964).

The current experiment indicates that generalization gradients may be obtained via a change in rate but without drastic changes in response patterning. Use of a probe technique may be the critical factor in elimination of alterations in response patterning which often occur using an extinction procedure. Such results provide an additional step in isolating the relevant parameters involved in generalization and indicate the need of closer scrutiny of data obtained in extinction testing.

\section{Referenees}

Antonitis, J. J. Response variability in the white rat during conditioning, extinction, and reconditioning. J. exp. Psychol., $1951,42,273-281$.

Blough, D. S. Interresponse time as a function of continuous variables: a new method and some data. J. exp. Anal. Behav. $1963,6,237-246$.

Guttman, N., \& Kalish, H. I. Discriminability and stimulus generalization. J. exp. Psychol., 1956, 51, 79-88.

Hearst, Eliot, Koresko, M. B., \& Poppen, R. Stimulus generalization and the response reinforcement contingency. $J$. exp. Anal. Behav., 1964, 7, 369-380.

Jenkins, H. M., \& Harrison, R. H. Effect of discrimination training on auditory generalization. J. exp. Psychol., 1960, 59, 246-253.

Millenson, J. R., \& Hurwitz, H. M. B. Some temporal and sequential properties of behavior during conditioning and extinction. J. exp. Anal. Behav., 1961, 4, 97-106.

Sewell, w. R. IRT distributions during generalization testing. A paper read at Southeastern Psychological Association, Atlanta, April 4, 1965.

Skinner, B, F. Are theories of learning necessary? Psychol. Rev., $1950,57,193-216$.

\section{Note}

1. Supported by National Institute of Mental Health Predoctoral Research Fellowship $1 \mathrm{~F} 1 \mathrm{MH}-24$ 644-01 to the first author. 